Preference is given to letters commenting on contributions published recently in the JRSM. They should not exceed 300 words and should be typed double spaced

\section{The liver in metabolic syndrome}

In their review article last year, Wilkin and Voss ${ }^{1}$ made no reference to the potential impact of the metabolic syndrome upon the liver. Non-alcoholic fatty liver disease (NAFLD) should be numbered among the consequences of insulin resistance, hyperinsulinaemia and continued weight gain. ${ }^{2}$ It encompasses a spectrum of liver injury ranging from uncomplicated macrovesicular steatosis on the one hand, through non-alcoholic steatohepatitis (NASH, i.e. steatosis, ballooning degeneration of hepatocytes, neutrophil infiltration and pericentral pericellular fibrosis) to cirrhosis and liver failure at the opposite extreme. NAFLD is now judged the most likely explanation for non-specific liver test abnormalities among patients referred for evaluation thereof. ${ }^{3}$ Furthermore, NASH may have been responsible for a substantial proportion of cases of cryptogenic cirrhosis referred for and undergoing orthotopic liver transplantation. ${ }^{4}$

The diagnosis of NAFLD should be considered in any patient who exhibits one or more components of the metabolic syndrome $^{5}$ and has abnormal liver tests, demonstrates clinical features of chronic liver disease, or both. As with other complications of the metabolic syndrome the more components that are present, the greater the likelihood that the patient has NAFLD. However, risk factors in and of themselves are not yet reliable predictors of the degree of fibrosis that may be present, and thus the extent of liver dysfunction and/or portal hypertension. ${ }^{2}$ Therefore, liver biopsy remains an important diagnostic tool among such patients.

In addition to increasing our understanding of the pathophysiology of NAFLD - e.g. which patients with uncomplicated steatosis may develop inflammation and fibrosis - it is vital that the potential impact of NASH and subsequent end-stage liver disease be appreciated and accepted by non-liver physicians. Otherwise, it may yet be the case that the burden of NASH upon liver transplant services will exceed that of chronic hepatitis $\mathrm{C}$ virus liver disease.

\section{Alastair D Smith}

Division of Gastroenterology and Hepatology,

Room 105 Bell Building, Duke University Medical Center, Trent Drive,

Durham NC 27710, USA

E-mail: alastair.smith@duke.edu

\section{REFERENCES}

1 Wilkin TJ, Voss LD. Metabolic syndrome: maladaptation to a modern world. J R Soc Med 2004;97:511-20

2 Charlton M. Nonalcoholic fatty liver disease: a review of current understanding and future impact. Clin Gastroenterol Hepatol 2004;2: $1048-58$
3 Clark JM, Brancati FL, Diehl AM. The prevalence and etiology of elevated aminotransferase levels in the United States. Am J Gastroenterol 2003;98:960-7

4 Contos MJ, Cales W, Sterling RK, et al. Development of nonalcoholic fatty liver disease after orthotopic liver transplantation for cryptogenic cirrhosis. Liver Transpl 2001;7:363-73

5 Angelico F, Del Ben M, Conti R, et al. Non-alcoholic fatty liver syndrome: a hepatic consequence of common metabolic diseases. $J$ Gastroenterol Hepatol 2003;18:588-94

\section{Nicotinic antagonists and nerve gas poisoning}

Whilst commending their article (March $2005 J_{R S M}^{1}$ ), we disagree with Dr Sheridan and his co-workers that use of a non-depolarizing neuromuscular blocker (NDNMB) would ever 'normalize function at the neuromuscular junction' in the case of nerve agent or organophosphate poisoning. In this instance any dose of NDNMBs would effect neuromuscular blockade through nicotinic receptor occupancy, thus augmenting the dual block associated with excessive intrasynaptic acetylcholine. ${ }^{2}$ In addition, we suggest that shorter-acting drugs such as cisatracurium or vecuronium are preferable to pancuronium and gallamine, since the latter are vagolytic (leading to inadvertent underdosing of antidotal atropine) and less amenable to careful titration in an intensive-care setting.

It would seem more rational to accept that paralysis is inevitable after significant exposure to nerve agents (necessitating ventilation), but to give large doses of NDNMBs anyway, in order to saturate nicotinic receptor binding sites with the idea of possibly preventing acetylcholine mediated receptor damage at the neuromuscular junction. NDNMBs could continue to be given by infusion, until either oxime therapy had achieved significant acetylcholinesterase reactivation, or sufficient acetylcholinesterase had been synthesized de novo. This rationale may help shorten the paralysis that occurs during the 'intermediate phase' of recovery from nerve agent poisoning.

Needless to say, this is an area that requires more research but in which research is very controversial. The development of a novel, short-acting acetylcholine chelator or inactivator might provide a possible antidote in cases of nerve agent or organophosphate poisoning.

\section{S M White}

\section{T M Palfreman}

Department of Anaesthesia, Royal Sussex County Hospital, Brighton BN2 5BE, UK E-mail: igasbest@hotmail.com

\section{REFERENCES}

1 Sheridan RD, Smith AP, Turner SR, Tattersall JEH. Nicotinic antagonists in the treatment of nerve agent poisoning. $J R$ Soc Med 2005;98114-15

2 White SM. Chemical and biological weapons. Implications for anaesthesia and intensive care. BrJ Anaesthesia 2002;89:306-24 


\section{Finger deformities in Renaissance art}

Dr Hijmans and Dr Dequeker presented an interesting argument for camptodactyly in the paintings of Dirk Bouts (November $2004 J R S M^{1}$ ). However, in their desire to distinguish these paintings from others of the period that show similar finger deformities, they misstate the nature of camptodactyly. Green's Operative Hand Surgery and the International Federation of Societies for Surgery of the Hand define camptodactyly as a congenital flexion deformity of the proximal interphalangeal joint of the fifth finger. ${ }^{2}$ Specifically, hyperextension of the distal interphalangeal joint is not necessary for the diagnosis; indeed, if this is present to a significant degree, the clinician should consider the possibility of a boutonnière deformity rather than camptodactyly. Also, extension of the metacarpophalangeal joint, while often present, is not a requirement for the diagnosis of camptodactyly.

While the exact cause of the deformity is not entirely known, it appears to be related to muscular abnormalities, particularly in the lumbrical or intrinsic muscles. It is present in both hands in two thirds of cases (in some, but not all, of the paintings by Bouts it is bilateral).

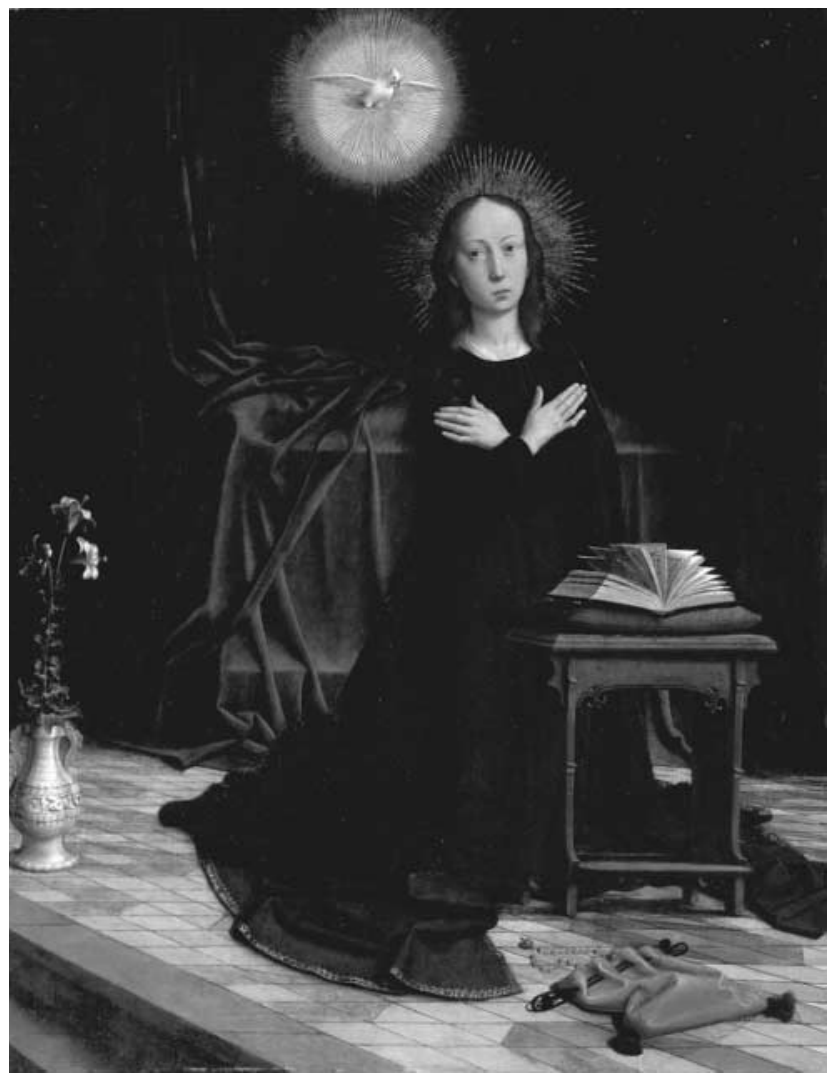

Figure 1 The Virgin, by Gerard David. The Metropolitan Museum of Art, Bequest of Mary Stillman Harkness, 1950
Shortly after reading the article by Hijmans and Dequeker I noted camptodactyly on one of the Christmas cards I was writing (Figure 1). This work, from the collection of the Metropolitan Museum of Art in New York, was painted by Gerard David (c. 1455-1523). Interestingly, this artist was independently mentioned by Dr Horton Johnson in his letter to the editor (February $\left.2005 J R S M^{3}\right)$ as one of several other examples of camptodactyly in art, although the painting he used was different.

In view of the number of artists and paintings that show evidence of camptodactyly (as defined by hand surgery authorities), it seems more likely that Bouts and his son were employing an artistic convention than that they were illustrating a hand deformity specific to their model.

\section{Christian Fras}

Department of Orthopedic Surgery, University of Pennsylvania, 3400 Spruce Street, Philadelphia, PA 19104, USA

\section{REFERENCES}

1 Hijmans W, Dequeker J. Camptodactyly in a painting by Dirk Bouts (c. 1410-1475). J R Soc Med 2004;97:549-51

2 Kay SPJ. Camptodactyly. In: Green DP, Hotchkiss RN, Pederson WC, eds. Green's Operative Hand Surgery, 4th edn. New York: Churchill Livingstone, 1999:510-17

3 Johnson HA. The Renaissance fifth finger. J R Soc Med 2005;98:87

\section{Autosurgery in women}

In a paper that attracted wide publicity last year MolinaSosa et al. ${ }^{1}$ reported the case of a Mexican woman who had performed a caesarean section on herself. An internet search had yielded no similar cases; however, I have found two instances of female autosurgery from earlier times.

The first case, reported in the Thessalonica newspaper Hermes in $1879,{ }^{2}$ was a woman from Radovo who, after being in labour for 48 hours with unbearable pains, took her husband's razor, opened her abdomen and uterus and removed the baby alive. Then, holding with her hands the edges of the incision, she asked her neighbour to stitch and close them, providing her with a needle and a silk thread. Mother and baby survived in excellent health. The other case was not of a caesarean section but of vaginal hysterectomy. Reported by Percival Willoughby in his Observations in Midwifery $(1670)^{3}$ it concerned a woman who, when lifting a bucket of coal, had experienced a sudden prolapse of the uterus. Many times she put the 'mass' back in place, only for it to return. One evening, abandoning all hope, she went into the garden with a kitchen knife and cut it away, along with 'some of the fleshy part of the bladder', subsequently fainting from blood loss. Though she lived for 
several years thereafter, she was incontinent, 'her water always coming night and day insensibly dribbling from her'. 3

\section{Christos Papaloucas}

Kymi General State Hospital, Kymi 34003, Greece

\section{REFERENCES}

1 Molina-Sosa A, Galvan-Espinosa H, Gabriel-Guzman J, Valle PF. Selfinflicted cesarean section with maternal and fetal survival. Int $J$ Gynaecol Obstet 2004;84:287-90

2 Pentogalos G. Obstetrics and gynaecology in the greater Macedonian area during the 19th century (1800-1912) [in Greek]. In: Proceedings of 5th Panhellenic Congress in Obstetrics and Gynaecology, Ioannina, 1991:260-3

3 Williams EA. Vaginal hysterectomy. J Obstet Gynaecol Br Commonw 1962;69:590-7

\section{Taking the sting out of needles}

I cannot, unfortunately, claim to be the wise mentor who taught Dr Yentis the seven principles of ensuring painless venous cannulation (April $2005 J R S M^{1}$ ): I can, however, claim that from 1978 I was teaching cohorts of medical students and anaesthetic novices the importance of using local anaesthesia before cannulation in conscious patients.

Of the reasons he puts forward for why doctors do not do what is known to work I suspect the third is correct: they accept the evidence but choose to disregard it. This is well summed up in the old adage 'That's a good idea: we won't implement it'. Other examples could be quoted. Before drugs such as ranitidine were introduced into obstetric anaesthesia it was often recommended that the patient's stomach should be emptied before inducing general anaesthesia. Holdsworth ${ }^{2}$ showed, somewhat surprisingly, that vomiting induced by apomorphine injection was considered much pleasanter by patients than the passage of a stomach tube. The two methods were equally effective and apomorphine had no deleterious effect on the baby. Nevertheless, the use of apomorphine was never widely accepted. Nott and Hughes ${ }^{3}$ showed that the use of an intranasal spray of lignocaine significantly reduced the discomfort caused by insertion of a nasogastric tube, but as far as I am aware this simple manoeuvre has not been universally adopted.

Patients remember staff who are kind and procedures that are painful or distressing. Wards and clinics provide a rich source of simple research projects that could enhance the comfort of patients and the CVs of doctors.

\section{Hugh Seeley}

2 Salisbury House, Somerset Road, London SW19 5HY, UK

E-mail: hseeley@doctors.org.uk

\section{REFERENCES}

1 Yentis S. Taking the sting out of needles. J R Soc Med 2005;98:139-40

2 Holdsworth JD. The place of apomorphine prior to obstetric analgesia. J Int Med Res 1978;6(suppl 1):26-9

3 Nott MR, Hughes JH. Topical anaesthesia for the insertion of nasogastric tubes. Eur J Anaesthesiol 1995;12:287-90

\section{Parkinsonism in a ham-seller}

Dr Budrys (April $2005 J R S M^{1}$ ) recognizes features of parkinsonism in Mr Kulik the ham-seller as portrayed by Isidore Weiss in 1814. From his name Weiss is Jewish, and probably Kulik also - in which case Kulik's affliction could be the artist's ironic comment on the penalties of selling unclean meat.

\section{Rodney Price}

West Yorkshire, UK

E-mail: BoneCutterLock@aol.com

\section{REFERENCE}

1 Budrys V. Parkinson's disease before Parkinson, Vilnius 1814. J R Soc Med 2005;98:178-9

\section{Integrated teams}

The Head of the Division of Medicine at University College London suggests that 'Reinvention of teams of doctors, nurses, therapists and social workers seems like an important task for general medicine' (May $2005 J R S M^{1}$ ). Perhaps he could visit an acute geriatric ward; they exist in almost all district general hospitals.

\section{Kalman Kafetz}

Department of Medicine for Elderly People,

Whipps Cross University Hospital, London E11 1NR, UK

E-mail: kalman.kafetz@whippsx.nhs.uk

\section{REFERENCE}

1 Vallance P. A post-take ward round. J R Soc Med 2005;98:191-2 